\title{
A nanoparticulate polyacetylene-supported Pd(II) catalyst combining the advantages of homogeneous and heterogeneous catalysts
}

\author{
Huan Li a,b,\#, Guangxu Chen a, Paul N. Duchesnec, Peng Zhang c, Yan Dai a, Huayan Yang a, \\ Binghui Wua, Shengjie Liu a, Chaofa Xua anfeng Zheng a,* \\ a State Key Laboratory for Physical Chemistry of Solid Surfaces, Collaborative Innovation Center of Chemistry for Energy Materials, Department of \\ Chemistry, College of Chemistry and Chemical Engineering, Xiamen University, Xiamen 361005, Fujian, China \\ b Institute of Crystalline Materials, Shanxi University, Taiyuan 030006, Shanxi, China \\ ' Department of Chemistry, Dalhousie University, Halifax B3H 4R2, Canada
}

\section{A R T I C L E I N F 0}

Article history:

Received 26 April 2015

Accepted 5 June 2015

Published 20 September 2015

Keywords:

Suzuki coupling

Acetylene

Palladium complex

Aqueous reaction

\begin{abstract}
A B S T R A C T
A novel nanoparticulate polyacetylene-supported Pd(II) catalyst (NP-Pd(II)) for use in the aqueous Suzuki-Miyaura cross coupling reaction was successfully synthesized by simply treating an aqueous solution of $\mathrm{PdCl}_{4}{ }^{2-}$ with acetylene under ambient conditions. Electron microscopy, Fourier transform infrared spectroscopy, Raman spectroscopy, X-ray diffraction, X-ray photoelectron spectroscopy and X-ray absorption spectroscopy were employed to characterize the NP-Pd(II) structure in detail. These analyses demonstrated that the Pd atoms in the NP-Pd(II) were present as $\mathrm{Pd}(\mathrm{II})$ and were coordinated with both the $\mathrm{Cl}$ atoms and the $\mathrm{C}=\mathrm{C}$ bonds of the polyacetylene. Both the homogeneous distribution of the $\mathrm{Pd}$ (II) along the polyacetylene backbone and the aggregation of the NP-Pd(II) in solution work in conjunction to make this material an ideal catalyst, combining the advantages of both homogeneous and heterogeneous catalysts.
\end{abstract}

(C) 2015, Dalian Institute of Chemical Physics, Chinese Academy of Sciences. Published by Elsevier B.V. All rights reserved.

\section{Introduction}

The development of efficient, cost-effective and recyclable catalysts is a constant challenge for industries working with chemical transformations [1,2], and transition metal complexes with atomically-dispersed active centers have become one of the most intensively studied systems for this purpose. These homogeneous catalysts have well-defined structures, allowing for the fine-tuning of their electronic and steric properties [2-4]. However, a tedious ligand screening process is typically necessary to optimize the stability, activity and selectivity of a homogenous catalyst. Moreover, this class of catalysts has the disadvantage of not being easily separated from the reaction mixture, presenting more than a few engineering issues $[5,6]$. Heterogeneous catalysts are a promising means of addressing the separation issue [7]. Unfortunately, intrinsically heterogeneous catalysts, such as supported metal nanoparticles, are usually less active than their homogeneous analogues. Heterogenization of homogeneous catalysts through chemical bonding on various supports, such as polymers or oxides, is an alternative strategy to mitigate the separation problem while maintaining high catalytic activity. In such cases, however, multistep

\footnotetext{
* Corresponding author. Tel: +86-592-2186821; Fax: +86-592-2183047; E-mail: nfzheng@xmu.edu.cn

\# Corresponding author. Tel: +86-351-7016082; E-mail: 59584340@sxu.edu.cn

This work was supported by Ministry of Science and Technology of China (2011CB932403, 2015CB932303) and the National Natural Science Foundation of China (221420102001, 21131005, 21390390, 21333008).

DOI: 10.1016/S1872-2067(15)60930-5 | http://www.sciencedirect.com/science/journal/18722067 | Chin. J. Catal., Vol. 36, No. 9, September 2015
} 
synthetic procedures are normally required, limiting their large-scale applications [8-12]. Thus, it would be highly desirable to develop a simple and efficient synthetic route for the preparation of materials combining the advantages of homogeneous and heterogeneous catalysts.

We report herein the effective one-step synthesis of a novel nanoparticulate polyacetylene-supported Pd(II) catalyst, denoted as NP-Pd(II), that functions as a highly efficient and recyclable catalyst for the Suzuki-Miyaura cross coupling reaction. This material was obtained by simply treating an aqueous solution of $\mathrm{PdCl}_{4}{ }^{2-}$ with acetylene under ambient conditions. Systematic characterization using electron microscopy, Fourier transform infrared (FT-IR) spectroscopy, Raman spectroscopy, X-ray diffraction (XRD), X-ray photoelectron spectroscopy (XPS) and extended X-ray absorption fine structure (EXAFS) analysis demonstrated that the resulting NP-Pd(II) contained micron-sized aggregates of fine nanoparticles composed of polyacetylene-supported Pd(II) complexes. The homogeneous distribution of Pd(II) along the polyacetylene backbone, combined with the tendency of the material to aggregate, makes NP-Pd(II) an ideal catalyst, with the advantages of both homogeneous and heterogeneous catalysts $[13,14]$. The prepared NP-Pd(II) was both air- and moisture-stable and exhibited high catalytic activity comparable to that of homogenous catalysts and better recyclability than carbon-supported Pd catalysts, especially in aqueous systems.

Because the Suzuki reaction is one of the most efficient methods of constructing biaryl and substituted aromatic molecules, its impact on both academic and industrial research has been immense [8,15-21]. To date, many Pd complexes have been applied as homogenous catalysts in the Suzuki reaction and the continual search for effective ligands has been one of the most fascinating aspects of this field. As an example, significant success has been achieved in using phosphine ligands, especially in conjunction with low-reactivity substrates [22-24]. Investigations of other ligands, such as N-heterocyclic carbenes [25-27], amines [28,29] and cyclic compounds [30], have also been widely reported in the literature. The demonstration of polyacetylene as an effective ligand for $\mathrm{Pd}(\mathrm{II})$ in this work further expands the range of ligands applicable to efficient Suzuki coupling catalysts. More importantly, the facile, one-step, readily scaled-up synthesis of NP-Pd(II) makes this heterogeneous Pd catalyst highly desirable for practical applications.

\section{Experimental}

\subsection{Synthesis of NP-Pd(II)}

A $\mathrm{H}_{2} \mathrm{PdCl}_{4}$ aqueous solution(20 mmol/L) was prepared by reacting $\mathrm{PdCl}_{2}$ with concentrated aqueous $\mathrm{HCl}$ in stoichiometric amounts at $70{ }^{\circ} \mathrm{C}$ for $1 \mathrm{~h}$. A suitable quantity of this aqueous solution was subsequently transferred to a glass pressure vessel and acetylene was introduced with stirring at ambient temperature $\left(25^{\circ} \mathrm{C}\right)$ while the relative pressure was maintained at $0.3 \mathrm{~atm}$ for $15 \mathrm{~min}$. On contact with the acetylene gas, the $\mathrm{H}_{2} \mathrm{PdCl}_{4}$ solution immediately became turbid. The resulting NP-Pd(II) was readily separated by centrifuging this colloidal suspension and the powder thus obtained was washed twice with $\mathrm{H}_{2} \mathrm{O}$ and ethanol, followed by further centrifugation. Finally, the NP-Pd(II) was dried under vacuum at $40^{\circ} \mathrm{C}$ overnight. Inductively coupled plasma (ICP) analysis of the resulting dry NP-Pd(II) confirmed almost complete conversion of the original $\mathrm{PdCl}_{4}{ }^{2-}$ to NP-Pd(II). This synthetic procedure was readily scaled up. As shown in Fig. S1, 1 g of NP-Pd(II) was successfully obtained from a larger scale reaction performed in a $250-\mathrm{mL}$ flask. Synthesis using an acetylene pressure of 1 atm rather than $0.3 \mathrm{~atm}$ gave a material termed NP-Pd(II)-1atm that was found to have a similar composition and morphology (Fig. S2) to the NP-Pd(II), and to generate similar XPS (Fig. S3) and FT-IR (Fig. S4(a)) spectra as well as exhibiting the same catalytic performance (Fig. S4(b)).

\subsection{A typical procedure for the NP-Pd(II)-catalyzed aqueous Suzuki coupling reaction}

In a glass vessel, $15 \mathrm{~mL} \mathrm{H}{ }_{2} \mathrm{O}, 212 \mathrm{mg} \mathrm{Na}_{2} \mathrm{CO}_{3}, 183 \mathrm{mg}$ phenylboronic acid and $112 \mu \mathrm{L}$ iodobenzene were added. The vessel was then placed into a pre-heated water bath and the reaction was initiated by adding $0.24 \mathrm{mg}$ NP-Pd(II). After the reaction was complete, diethyl ether $(3 \times 3 \mathrm{~mL})$ was added to extract the products for gas chromatographic (GC) analysis. The prod-

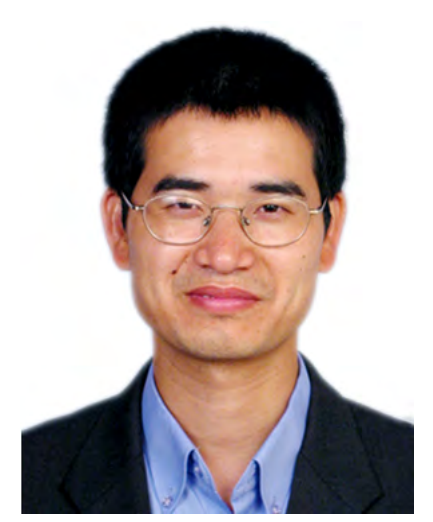

Zheng Nanfeng (College of Chemistry and Chemical Engineering, Xiamen University) received Chinese Chemical Society-Royal society of Chemistry Young Chemist Award (2014), which was presented by the Chinese Chemical Society and the Royal Society of Chemistry. Prof. Zheng received his B.S. from the Department of Chemistry, Xiamen University in 1998. In 2005, he obtained his Ph.D. degree from the Department of Chemistry, University of California-Riverside supervised by Prof. Pingyun Feng. His thesis was on the synthesis and characterization of chalcogenide nanoclusters and their superstructures. During 2005-2007, he worked on gold catalysis with Prof. Galen D. Stucky as a research associate at University of California-Santa Barbara. In 2007, he moved to Xiamen University as a full professor. He is currently a Changjiang Chair professor at Xiamen University. His research interests mainly focus on the development of advanced functional materials for both fundamental research and practical applications, particularly in the fields of catalysis and biology. His ultimate goal is to gain understanding of the synthesis, properties and also applications of functional nanomaterials at the molecular level. Most of current research efforts of his group are directed to surface and interfacial chemistry of functional materials, and nanocluster chemistry. 
ucts, still in diethyl ether, were analyzed by GC-mass spectrometry (MS) by comparison with standard samples of the expected products, and the extent of conversion was determined using $n$-heptane as an internal standard. With the exception of $p$-iodoanisole, which gave a small amount of biphenyl as by-product, most substrates exhibited complete selectivity for the desired product. The turnover frequency (TOF) of each reaction was typically calculated as the substrate turnover per mole of Pd per hour at a given temperature. To compare the results of the present study with results previously reported in the literature, the trials used to determine TOF values were conducted under similar conditions in terms of solvents and temperature. In recycling tests, the diethyl ether layer was carefully removed and fresh substrates were then added for further reaction under the same conditions.

\subsection{EXAFS Analyses}

The EXAFS studies of NP-Pd(II) were conducted at the 01C1 beamline of the National Synchrotron Radiation Research Center (NSRRC) at Hsinchu, Taiwan. A standard fluorescence configuration was employed, using an in-line metal reference foil for energy calibration. The NP-Pd(II) was dissolved in approximately $2 \mathrm{~mL}$ ethanol prior to analysis. Data processing and fitting were performed using the commercially available WinXAS and FEFF8 software packages. The resulting XAFS spectrum in $k$-space is shown in Fig. S5, over the range of 3 to $12 \AA$. EXAFS fitting was performed only over the region of interest (1.28-2.40 $\mathrm{A}$ ). More details of the fitting method applied to the Fourier-transformed EXAFS spectrum are provided in Supporting Information.

\section{Results and discussion}

As noted, a typical synthesis of NP-Pd(II) was carried out by treating an aqueous solution of $\mathrm{PdCl}_{4}{ }^{2-}$ with acetylene at room temperature. After collecting the product by centrifugation and washing with $\mathrm{H}_{2} \mathrm{O}$ and ethanol, the NP-Pd(II) was obtained in the form of a brown-red powder (Supporting Information). The morphology of the NP-Pd(II) was characterized using transmission electron microscopy (TEM), and the TEM image in Fig. 1(a) shows that the obtained NP-Pd(II) was primarily in the form of spherical particles with an average diameter of approximately $100 \mathrm{~nm}$. A high-magnification TEM image (Fig. 1(b)) further reveals that the as-prepared NP-Pd(II) particles were actually aggregates of very fine nanoparticles (FNPs) with diameters of 2-3 $\mathrm{nm}$. Interestingly, when polyvinylpyrrolidone (PVP, 30K) was introduced to an aqueous dispersion of NP-Pd(II) with vigorous stirring, the aggregated particles were disassembled into isolated FNPs with a mean particle size of 2.8 $\pm 0.4 \mathrm{~nm}$ (Fig. 1(c) and (d)). This disassembly process suggests that the interaction between the FNP subcomponents was weak. The aggregation of FNPs into much larger NP-Pd(II) particles in water could be driven by their hydrophobic nature and the associated minimization of the total surface energy. Together with its aggregating nature, the hydrophobic nature of NP-Pd(II) allows the catalyst to be readily separated from wa-
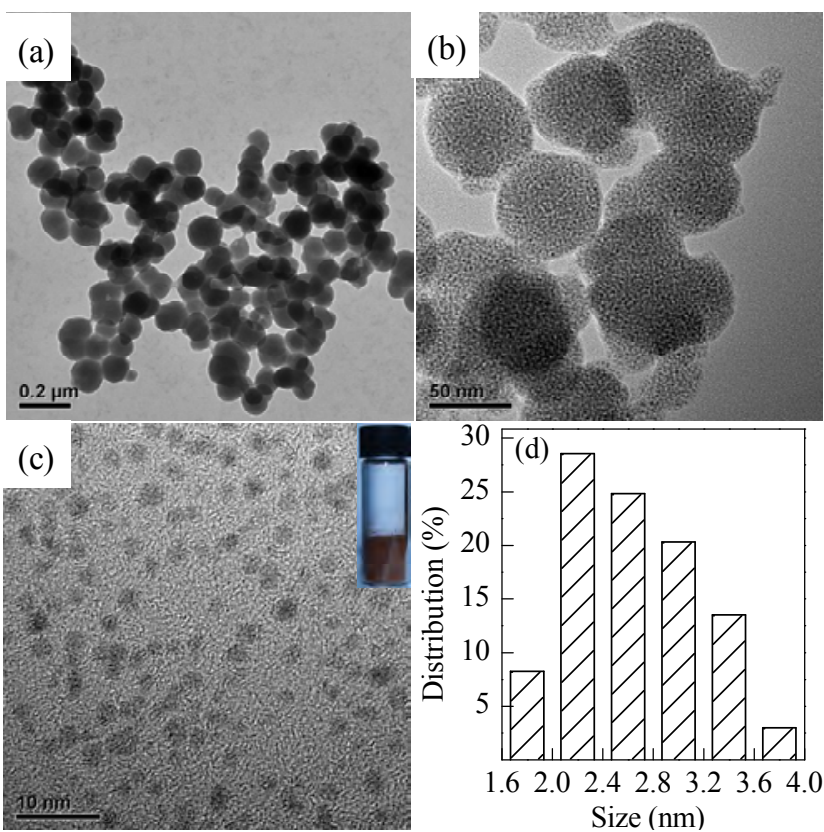

Fig. 1. TEM images of NP-Pd(II) at low (a) and high (b) magnifications and after treatment with PVP (c). (d) is the size distribution of the fine nanoparticles of NP-Pd(II).

ter via either centrifugation or static settlement. Moreover, the synthesis of NP-Pd(II) may be readily scaled up to allow for mass production as a result of the one-step process and mild reaction conditions. As noted above, in our laboratory, NP-Pd(II) was successfully prepared on the gram scale using the newly developed synthetic method (Fig. S1).

Elemental analyses using ICP-MS and a CHN analyzer determined that the $\mathrm{Pd}, \mathrm{C}, \mathrm{H}$ and $\mathrm{Cl}$ proportions in the NP-Pd(II) were $44.9 \%, 22.0 \%, 2.4 \%$ and $30.7 \%$, respectively, thus the Pd:C:Cl ratio was approximately 1.0:4.3:2.1. Despite the high percentage of $\mathrm{Pd}$, the XRD pattern of NP-Pd(II) displays no obvious diffraction peaks, indicating the absence of metallic $\mathrm{Pd}$ nanoparticles and the amorphous nature of the NP-Pd(II) (Fig. 2(a)). However, the electron beam-induced formation of metallic Pd nanoparticles was observed during TEM measurements, and so XPS was used to determine the oxidation state of Pd in the NP-Pd(II). Fig. 2(b) shows a Pd $3 d$ doublet at binding energies of 341.7 and $336.6 \mathrm{eV}$, corresponding to $3 d_{3 / 2}$ and $3 d_{5 / 2}$, respectively. The binding energy of the $\mathrm{Pd} 3 d_{5 / 2}$ peak with good symmetry at $336.6 \mathrm{eV}$ was significantly higher than that of $\mathrm{Pd}$ foil (ca. $335 \mathrm{eV}$ ), but close to that of PdO [31]. This result indicated that the Pd in the NP-Pd(II) was likely in the +2 oxidation state. In addition, the binding energy of this $\mathrm{Pd} 3 d_{5 / 2}$ peak was still $1.6 \mathrm{eV}$ lower than that of the precursor $\mathrm{PdCl}_{4}{ }^{2-}$ [32], suggesting that the $\mathrm{Pd}$ in the catalyst was no longer coordinated to four $\mathrm{Cl}^{-}$ligands.

The FT-IR spectrum of the NP-Pd(II) was acquired to determine the coordination structure of the Pd(II). The IR spectrum in Fig. 3(a) clearly shows two prominent bands at 1665 and $1605 \mathrm{~cm}^{-1}$, attributed to the stretching vibrations of conjugated $\mathrm{C}=\mathrm{C}$ bonds $(v(\mathrm{C}=\mathrm{C}))$. A peak at $3016 \mathrm{~cm}^{-1}$, corresponding to the stretching absorption of $=\mathrm{C}-\mathrm{H}(v(=\mathrm{C}-\mathrm{H}))$, was also observed (Fig. S7). No absorption bands corresponding to the 

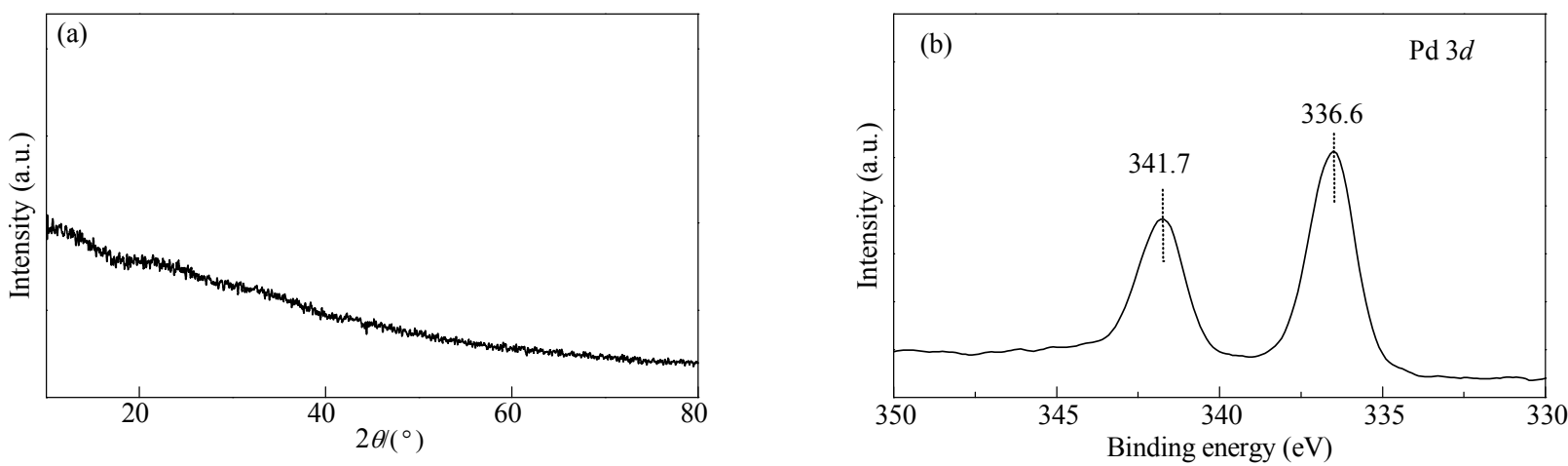

Fig. 2. XRD (a) and XPS (b) patterns of NP-Pd(II).

triple bond stretching mode $(v(\mathrm{C} \equiv \mathrm{C})$ ) of free acetylene ( $c a$. $\left.2100 \mathrm{~cm}^{-1}\right)$ or to coordinated $\mathrm{Pd}\left(\mathrm{ca} .1800 \mathrm{~cm}^{-1}\right)$ were present in the spectrum [33]. These results suggest that the polymerization of acetylene into conjugated alkenes took place in the presence of $\mathrm{Pd}(\mathrm{II})$, as has been well documented in the literature [34]. The formation of polyacetylene was also confirmed by the presence of IR absorption peaks in the region of 700 to $950 \mathrm{~cm}^{-1}$, corresponding to the out-of-plane bending vibrations of $=\mathrm{CH}(\delta(=\mathrm{CH}))$. Typically, the stretching mode of $\mathrm{C}=\mathrm{C}$ generates medium or even weak peaks. In our case, however, the $v(\mathrm{C}=\mathrm{C})$ peak appeared to exhibit the strongest IR absorption. This can be explained by the polarization of double bonds, likely caused by their coordination with $\mathrm{Pd}$, and the conjugation of the $\mathrm{C}=\mathrm{C}$ bonds in polyacetylene (vide infra). The polymerization of acetylene was further supported by solid-state ${ }^{1} \mathrm{H}$ NMR analysis of the NP-Pd(II), since the resulting spectrum showed a broad peak with a chemical shift centered at 5 ppm (Fig. S8), characteristic of the ${ }^{1} \mathrm{H}$ chemical shift of alkenes [35].

The coordination environment of the $\mathrm{Pd}$ was significantly changed with the formation of the NP-Pd(II), and so the UV-Vis absorption spectrum of the catalyst was different from that of the $\mathrm{PdCl}_{4}{ }^{2-}$ precursor (Fig. S9). The aqueous $\mathrm{PdCl}_{4}^{2-}$ solution generated an absorption band at $218 \mathrm{~nm}$ with a shoulder at $243 \mathrm{~nm}$, corresponding to the ligand-to-metal charge transfer absorptions of $\left[\mathrm{PdCl}_{3}\left(\mathrm{H}_{2} \mathrm{O}\right)\right]^{-}$and $\left[\mathrm{PdCl}_{2}\left(\mathrm{H}_{2} \mathrm{O}\right)_{2}\right]$ [36]. In comparison, the NP-Pd(II) spectra contained only one prominent peak at $289 \mathrm{~nm}$, clearly indicating a variation in the Pd coordination environment. The high background intensity in the NP-Pd(II) spectrum was ascribed to light scattering induced by

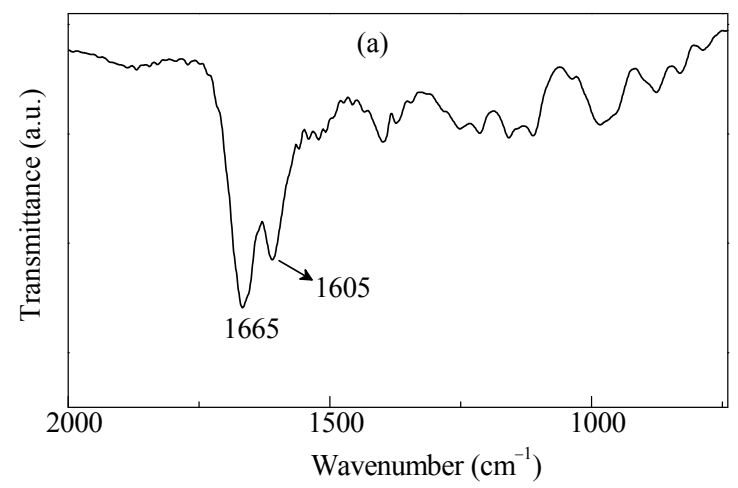

NP-Pd(II) colloids. To further determine the Pd coordination in the NP-Pd(II), Raman spectroscopy was also employed. As can be seen from Fig. 3(b), the Raman spectrum of NP-Pd(II) displays two intense peaks, at 1260 and $423 \mathrm{~cm}^{-1}$. The band at $423 \mathrm{~cm}^{-1}$ is assigned to the $\mathrm{Pd}-\mathrm{C}=\mathrm{C}$ stretching mode, while the peak at $1260 \mathrm{~cm}^{-1}$ is attributed to the strongly coupled C-C and $\mathrm{C}=\mathrm{C}$ stretching modes $[37,38]$. The weak peak at $274 \mathrm{~cm}^{-1}$ is assigned to the Pd-Cl stretching mode [39]. These results indicate that the $\mathrm{Pd}$ atoms in the NP-Pd(II) were coordinated to both $\mathrm{Cl}$ and $\mathrm{C}=\mathrm{C}$ moieties. The coordination of $\mathrm{C}=\mathrm{C}$ to $\mathrm{Pd}$ is also supported by the presence of two weak bands at 1523 and $1428 \mathrm{~cm}^{-1}$ in NP-Pd(II), corresponding to the stretching vibration of $\mathrm{C}=\mathrm{C}$ coordinated with $\mathrm{Pd}$. In FT-IR spectra, $\mathrm{C}=\mathrm{C}$ bonds coordinated with $\mathrm{Pd}$ are expected to absorb at lower wavenumbers as compared to non-coordinated bonds [31]. Moreover, the solid state ${ }^{13} \mathrm{C}$ NMR spectrum (Fig. S8) also confirmed the coordination of $\mathrm{C}=\mathrm{C}$ bonds with $\mathrm{Pd}$ in the NP-Pd(II) based on the presence of a peak at a chemical shift of $80 \mathrm{ppm}[40,41]$.

Since the first such report in 1984, there has been significant interest in the study of polymeric complexes obtained by reacting a $\mathrm{Pd}(\mathrm{II})$ precursor with various acetylene derivatives [34,42-44]. However, the detailed structures of these polymeric Pd complexes have rarely been studied by EXAFS [45]. To gain a deeper understanding of the local structure of the Pd in this material, fluorescence-mode XAS was also performed on the NP-Pd(II) at the Pd K-edge (24.35 keV) (Fig. S5). The radial distribution function obtained by Fourier transformation of the $k^{3}$-weighted EXAFS data for NP-Pd(II) is shown in Fig. 4(a), together with results for $\mathrm{Pd}$ foil and $\mathrm{Na}_{2} \mathrm{PdCl}_{4}$ for comparison

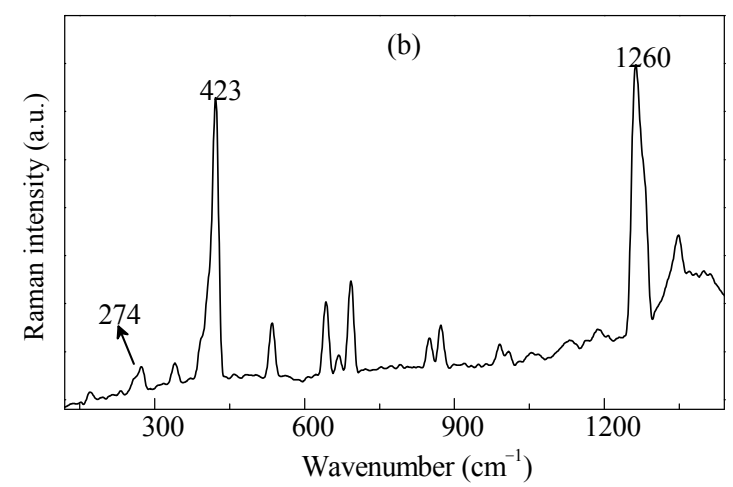

Fig. 3. FT-IR (a) and Raman (b) spectra of NP-Pd(II). 

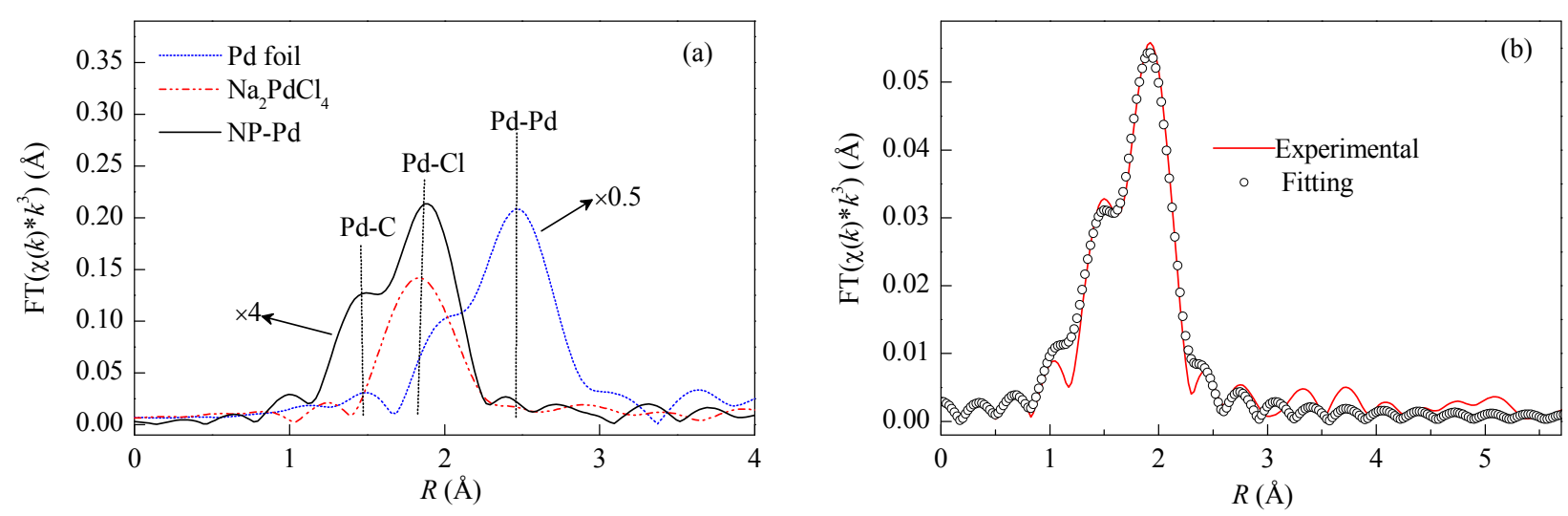

Fig. 4. (a) EXAFS spectra of NP-Pd(II), $\mathrm{Na}_{2} \mathrm{PdCl}_{4}$, Pd foil; (b) curve fitting for the NP-Pd(II) data.

purposes. The EXAFS peak centered at approximately $2 \AA$ can be attributed to the $\mathrm{Pd}-\mathrm{Cl}$ coordination shell. A peak at the same position was also observed in the case of the $\mathrm{Na}_{2} \mathrm{PdCl}_{4}$ reference, in which Pd is coordinated only to $\mathrm{Cl}^{-}$. The shoulder at approximately $1.5 \AA$ indicates the presence of very short Pd-ligand bonds, identified as a Pd-C coordination shell by the EXAFS fitting discussed below. The absence of Pd-Pd scattering further excludes the presence of metallic Pd in the NP-Pd(II). The XAS results also ruled out the presence of PdO (Fig. S10). Therefore, two coordination shells, $\mathrm{Pd}-\mathrm{C}$ and $\mathrm{Pd}-\mathrm{Cl}$, were introduced to fit the EXAFS spectrum as a means of obtaining more precise coordination information for the $\mathrm{Pd}$ in the NP-Pd(II) (Fig. 4(b)). As shown in Table 1, quantitative analysis of the EXAFS spectra demonstrated that the Pd atoms had average coordination numbers of 2.2 and 2.4 for the Pd-C and Pd-Cl scattering paths, respectively (see also Supporting Information). Attempts to introduce an extra Pd-Pd coordination shell led to unreasonable fitting results.

Based on a combination of the spectroscopic results and EXAFS fitting data, we propose two possible models for the local structure of Pd in this material (Fig. S11). In the first model, $\mathrm{Pd}$ atoms are present as dimers bridged by two $\mathrm{Cl}^{-}$. In addition to one bridging $\mathrm{Cl}^{-}$, each $\mathrm{Pd}$ atom is also coordinated to one $\mathrm{C}=\mathrm{C}$ unit and a terminal $\mathrm{Cl}^{-}$, giving coordination numbers of 2 and 3 for $\mathrm{Pd}-\mathrm{C}$ and $\mathrm{Pd}-\mathrm{Cl}$, respectively. In the second model, one $\mathrm{Pd}$ atom is coordinated with two double bonds and two terminal Cl- ligands, giving coordination numbers of 4 and 2 to Pd-C and $\mathrm{Pd}-\mathrm{Cl}$, respectively. It should be noted that both of these structures are common in acetylene complexes of Pd [46]. Reacting olefins with appropriate Pd precursors has also been shown to yield similar products [44]. The co-presence of both coordination patterns in the NP-Pd(II) was also indicated by

Table 1

Fitting results for the NP-Pd(II) EXAFS data. ${ }^{\mathrm{a}}$

\begin{tabular}{lcccc}
\hline $\begin{array}{l}\text { Scattering } \\
\text { path }{ }^{\mathrm{b}}\end{array}$ & $\begin{array}{c}\text { C. N. } \mathrm{c} \\
\text { /atoms }\end{array}$ & Bong length $/ \AA$ & $\begin{array}{c}\text { Debye-Waller } \\
\text { factor } / \AA^{2}\end{array}$ & $E_{0}$-shift/eV \\
\hline $\mathrm{Pd}-\mathrm{C}$ & $2.2 \pm 0.5$ & $2.09 \pm 0.026$ & $0.007 \pm 0.002$ & $4 \pm 2$ \\
$\mathrm{Pd}-\mathrm{Cl}$ & $2.4 \pm 0.5$ & $2.38 \pm 0.015$ & $0.007 \pm 0.002$ & $4 \pm 2$ \\
\hline
\end{tabular}

a To reduce the number of free-running parameters, Debye-Waller factors and $E_{0}$-shifts were assumed to be equal for both paths. ${ }^{\text {b Scat- }}$ tering path of the photoelectron. ${ }^{\mathrm{c}}$ Coordination number. the results of FT-IR spectroscopy. Absorption peaks corresponding to both coordinated (1523 and $\left.1428 \mathrm{~cm}^{-1}\right)$ and free $\mathrm{C}=\mathrm{C}$ bonds $\left(1665\right.$ and $\left.1605 \mathrm{~cm}^{-1}\right)$ were observed in the FT-IR spectrum of NP-Pd(II).

Based on the above analyses, the NP-Pd(II) comprised aggregated amorphous polyacetylene-supported Pd(II) nanoparticles, in which the Pd(II) atoms were atomically dispersed in the polyacetylene matrix. These structural features should make the NP-Pd(II) a desirable catalyst, and so Suzuki cross coupling reactions were performed using this material so as to evaluate its catalytic activity and recyclability. To fairly establish an activity ranking of NP-Pd(II) among different Pd catalysts, a model reaction employing iodobenzene and phenylboronic acid was first conducted in a mixed solvent of ethanol and deionized $\mathrm{H}_{2} \mathrm{O}$. Various other Pd catalysts, including $\mathrm{Pd}(\mathrm{OAc})_{2},\left(\mathrm{CH}_{3} \mathrm{CN}\right)_{2} \mathrm{Cl}_{2} \mathrm{Pd}$ (denoted as $\left.\mathrm{CNCl}-\mathrm{Pd}\right),\left(\mathrm{Ph}_{3} \mathrm{P}\right)_{4} \mathrm{Pd}$ and $\mathrm{Pd} / \mathrm{C}$ (Aldrich, $10 \mathrm{wt} \% \mathrm{Pd}$ on activated carbon) were chosen for comparison. As shown in Fig. 5(a), NP-Pd(II) exhibited catalytic activity comparable to that of each of the homogeneous catalysts $\left(\mathrm{CNCl}-\mathrm{Pd},\left(\mathrm{Ph}_{3} \mathrm{P}\right)_{4} \mathrm{Pd}\right.$ and $\left.\mathrm{Pd}(\mathrm{OAc})_{2}\right)$ and remarkably better than that of Pd/C. After $0.5 \mathrm{~h}$ reactions, the iodobenzene conversions were $79 \%, 82 \%, 76 \%, 56 \%$ and $24 \%$ for NP-Pd(II), $\mathrm{CNCl}-\mathrm{Pd}, \mathrm{Pd}(\mathrm{OAc})_{2},\left(\mathrm{Ph}_{3} \mathrm{P}\right)_{4} \mathrm{Pd}$ and $\mathrm{Pd} / \mathrm{C}$, respectively. Thus, although NP-Pd(II) is essentially a heterogeneous catalyst, its activity was equal to or even better than that of homogeneous catalysts. Such high activity indicates that the Pd atoms in the NP-Pd(II) were highly accessible and that the $\mathrm{C}=\mathrm{C}$ ligands derived from acetylene were effective for Suzuki coupling. In fact, the positive effect of $\mathrm{C}=\mathrm{C}$ ligands on Pd-catalyzed cross-coupling has been recently summarized [47].

To illustrate the advantages of NP-Pd(II), the durability of the NP-Pd(II) catalyst was also compared with that of Pd/C and the most active homogeneous catalyst, $\mathrm{CNCl}-\mathrm{Pd}$, by reducing the Pd loading to $0.002 \mathrm{~mol} \%$. As shown in Fig. 5(b), after $2 \mathrm{~h}$ reactions, the NP-Pd(II) and CNCl-Pd gave iodobenzene conversion of 60 and 63\%, respectively, while the $\mathrm{Pd} / \mathrm{C}$ allowed only an $8 \%$ conversion. When the reaction time was extended, the $\mathrm{CNCl}-\mathrm{Pd}$ did not produce appreciably higher conversions; after $12 \mathrm{~h}$, the conversion over CNCl-Pd was only increased to $65 \%$, indicating deactivation of the catalyst. In comparison, the NP-Pd(II) exhibited distinctly better performance, giving a 

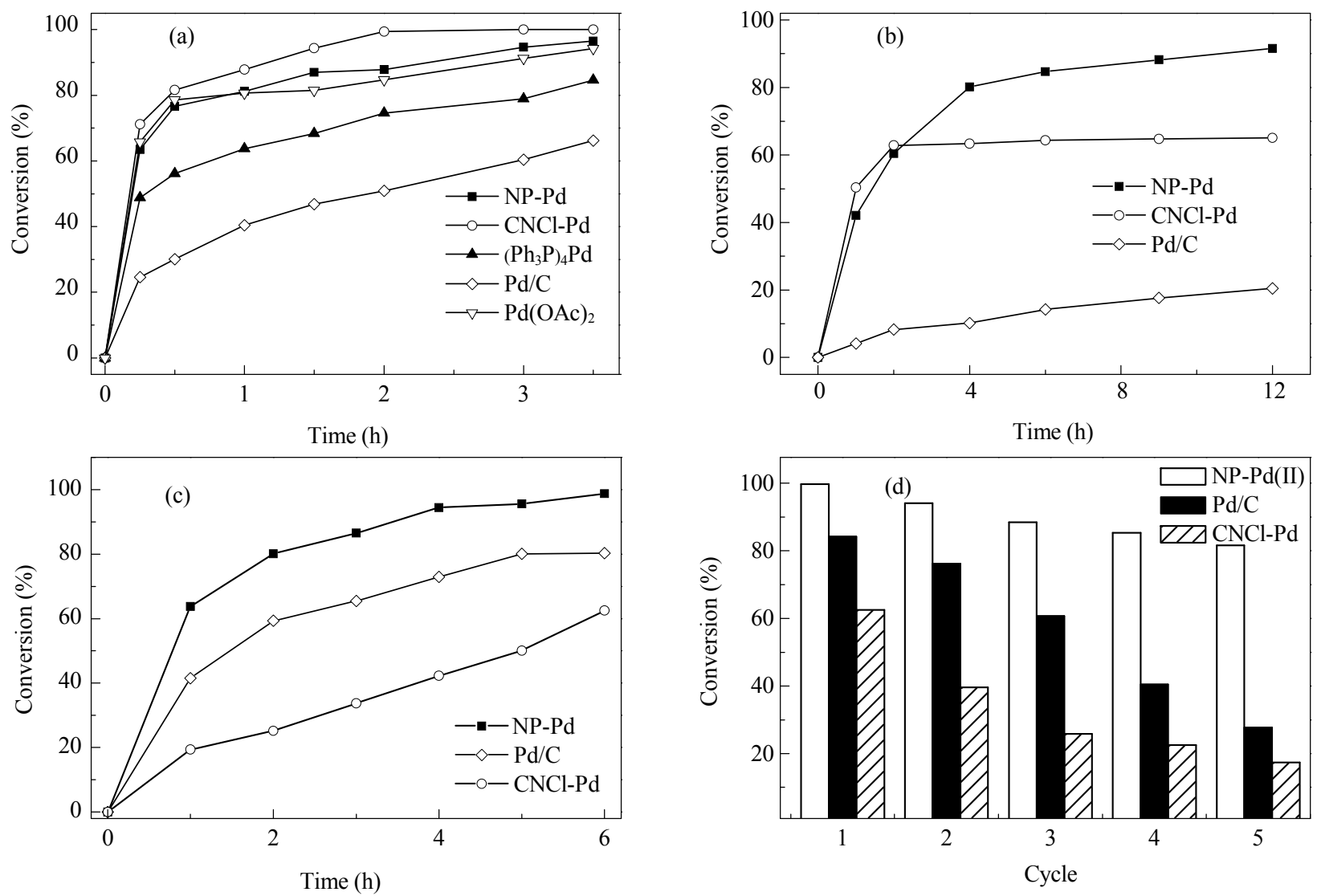

Fig. 5. Performance of NP-Pd(II) during the Suzuki coupling of iodobenzene with phenylboronic acid inmixed solvents (a, b) and $\mathrm{H}_{2} \mathrm{O}$ (c, d). Reaction conditions: (a) $0.1 \mathrm{~mol} \% \mathrm{Pd}, 10 \mathrm{~mL}$ ethanol, $5 \mathrm{~mL} \mathrm{H} \mathrm{H}_{2} \mathrm{O}, 1 \mathrm{mmol}$ iodobenzene, $1.5 \mathrm{mmol}$ phenylboronic acid, $2 \mathrm{mmol} \mathrm{Na}_{2} \mathrm{CO}_{3}, 30^{\circ} \mathrm{C}$. Reaction conditions changed relative to (a): (b) $0.002 \mathrm{~mol} \% \mathrm{Pd}$; (c) solvent: $15 \mathrm{~mL} \mathrm{H}_{2} \mathrm{O}$; (d) solvent: $15 \mathrm{~mL} \mathrm{H} \mathrm{O}_{2}, 60^{\circ} \mathrm{C}, 1 \mathrm{~h}$.

conversion of $90 \%$ after $12 \mathrm{~h}$. In other trials, a reaction temperature of $80{ }^{\circ} \mathrm{C}$ was found to generate almost complete conversion within $1 \mathrm{~h}$. As well, further lowering the Pd loading to 0.00025 mol\% gave $52 \%$ conversion within $1 \mathrm{~h}$ at $80^{\circ} \mathrm{C}$, corresponding to a TOF as high as 208000 . This value is much greater than the highest value achieved using heterogeneous catalysts [48] and also shows a much more effective reaction promotion than that of many homogeneous catalysts [8]. After $6 \mathrm{~h}, 98 \%$ of the iodobenzene was converted, equivalent to a turnover number of 390000 (Fig. S12). Moreover, unlike many phosphine-based Pd complexes, the NP-Pd(II) was relatively stable. After storage for 6 months in open air at room temperature, no changes were observed in the FT-IR spectrum of the material nor did it exhibit any decrease in catalytic activity (Fig. S7 and S13).

$\mathrm{H}_{2} \mathrm{O}$ is an abundant, environmentally-friendly solvent and so there has been much research regarding Suzuki cross coupling reactions in aqueous systems [49-54]. To further demonstrate the advantages of NP-Pd(II), its catalytic performance in Suzuki coupling in water was investigated. CNCl-Pd has recently been used as a catalyst in aqueous Suzuki coupling [53], but the present work revealed that CNCl-Pd is less active than the NP-Pd(II) under such conditions. Trials showed that this material yielded only $20 \%$ conversion of iodobenzene within $1 \mathrm{~h}$, while also clearly generating Pd black during the reaction. In comparison, under the same conditions, conversions of $63 \%$ and $41 \%$ were achieved when using the NP-Pd(II) and Pd/C, respectively (Fig. 5(c)). A similar trend was also observed for the coupling of bromobenzene with phenylboronic acid. While a biphenyl yield of $97 \%$ was achieved with the NP-Pd(II) in $3 \mathrm{~h}$ at $70{ }^{\circ} \mathrm{C}$, the yields were $56 \%$ and $64 \%$ with the $\mathrm{CNCl}-\mathrm{Pd}$ and $\mathrm{Pd} / \mathrm{C}$, respectively, under the same conditions (Table 2, entries 1-3). These results indicate that the NP-Pd(II) is a more effective catalyst in the aqueous phase. Furthermore, the NP-Pd(II) catalyst exhibited much better stability and thus recyclability in aqueous Suzuki coupling reactions. In these studies, products from each reaction were extracted using diethyl ether and the catalysts were re-used in a subsequent reaction. As clearly shown in Fig. 5(d), after five cycles, the NP-Pd(II) continued to catalyze the coupling reaction, with a conversion of $82 \%$. In comparison, after five replicate reaction cycles, the $\mathrm{Pd} / \mathrm{C}$ and CNCl-Pd gave conversions of only $28 \%$ and $17 \%$, respectively. It is worth repeating that, due to its tendency toward aggregation, the NP-Pd(II) is easily separated from reaction solutions by centrifugation or simple settlement, making it highly applicable as a recyclable catalyst.

The NP-Pd(II) deactivation mechanism was also investigated. FT-IR spectra and elemental analysis did not indicate any obvious differences between the fresh and recycled catalysts (Fig. S7). However, high-resolution TEM (HRTEM) assessments 
Table 2

Suzuki coupling reactions with NP-Pd(II) in $\mathrm{H}_{2} \mathrm{O}$.

\begin{tabular}{|c|c|c|c|c|c|}
\hline Entry & Catalyst & Ar-X & $T /{ }^{\circ} \mathrm{C}$ & $t / \mathrm{h}$ & Yield a/\% \\
\hline 1 & NP-Pd(II) & & 70 & 3 & 97 \\
\hline 2 & $\mathrm{Pd} / \mathrm{C}$ & & 70 & 3 & 64 \\
\hline 3 & CNCl-Pd & & 70 & 3 & 56 \\
\hline $4^{b}$ & CNCl-Pd & & 70 & 3 & 94 \\
\hline 5 & NP-Pd(II) & & 40 & 1 & 98 \\
\hline 6 & $\mathrm{CNCl}-\mathrm{Pd}$ & & 40 & 1 & 94 \\
\hline 7 & $\mathrm{Pd} / \mathrm{C}$ & & 40 & 1 & 64 \\
\hline 8 & NP-Pd(II) & & 60 & 1 & 99 \\
\hline 9 & NP-Pd(II) & & 60 & 1 & 99 \\
\hline 10 & NP-Pd(II) & & 70 & 3 & 97 \\
\hline 11 & NP-Pd(II) & & 80 & 8 & 82 \\
\hline 12 & NP-Pd(II) & & 70 & 3 & 99 \\
\hline 13 & NP-Pd(II) & & 70 & 8 & 99 \\
\hline 14 & NP-Pd(II) & & 40 & 1 & 94 \\
\hline 15 & NP-Pd(II) & & 70 & 3 & 98 \\
\hline 16 & NP-Pd(II) & & 80 & 6 & 96 \\
\hline 17 & NP-Pd(II) & & 80 & 8 & 51 \\
\hline $18^{c}$ & NP-Pd(II) & & 80 & 10 & 91 \\
\hline 19 & NP-Pd(II) & & 60 & 8 & 95 \\
\hline 20 & NP-Pd(II) & & 70 & 3 & 98 \\
\hline 21 & NP-Pd(II) & & 70 & 3 & 99 \\
\hline 22 & NP-Pd(II) & & 70 & 10 & 75 \\
\hline
\end{tabular}

Reaction conditions: $0.1 \mathrm{~mol} \% \mathrm{Pd}, 15 \mathrm{~mL} \mathrm{H}_{2} \mathrm{O}, 1 \mathrm{mmol}$ benzene halide, $1.5 \mathrm{mmol}$ phenylboronic acid, $2 \mathrm{mmol} \mathrm{Na}_{2} \mathrm{CO}_{3} . \mathrm{R}=-\mathrm{H},-\mathrm{Cl},-\mathrm{CH}_{3}$ and $-\mathrm{CH}=\mathrm{CH}_{2}$ for entries $1-19,20,21$ and 22 . ${ }^{a} \mathrm{GC}$ yield. ${ }^{\mathrm{b}} 10 \mathrm{~mol} \% \mathrm{TBAB}$ added. ${ }^{\mathrm{c}} 0.5 \mathrm{~mol} \%$ Pd loading.

found metallic Pd nanoparticles in the used catalyst (Fig. S14), a finding that was verified by XRD and XPS data (Fig. S15 and Fig. S16). The mechanism by which these nanoparticles were formed was investigated using XAS analyses of NP-Pd(II) samples subjected to different treatments. Combining the NP-Pd(II) with only $\mathrm{Na}_{2} \mathrm{CO}_{3}$, iodobenzene or phenylboronic acid in $\mathrm{H}_{2} \mathrm{O}$ generated no changes in its EXAFS spectrum, indicating that the formation of metallic Pd was not induced by any individual component of the reaction mixture. However, following the reaction, the Pd-Pd coordination shell was clearly observed in the spectrum of used NP-Pd(II) (Fig. S17), demonstrating that the metallic Pd nanoparticles were formed during catalysis. Accordingly, we ascribe the gradual loss of activity of the NP-Pd(II) to the formation of less active Pd nanoparticles.

One of the most significant challenges associated with using aqueous Suzuki coupling is that the majority of halogenated aromatics are hydrophobic. As such, the lack of effective contact between the hydrophilic CNCl-Pd and the substrate was likely the main reason for its poor performance in $\mathrm{H}_{2} \mathrm{O}$. Accordingly, $10 \mathrm{~mol} \%$ tetrabutylammonium bromide, a commonly used phase-transfer reagent for aqueous Suzuki coupling [55], was added to enhance the activity of the CNCl-Pd, and a significant improvement was obtained, increasing the yield from $56 \%$ to $94 \%$ (Table 2, entry 4 ). When the relatively hydrophilic substrate 4-bromophenol was used, high yields were achieved with both the NP-Pd(II) and CNCl-Pd (Entries 5 and 6). The superior activity of the NP-Pd(II) compared to CNCl-Pd was therefore attributed to its polyacetylene ligands and unique morphology, both of which allow more effective contact between the catalyst and hydrophobic substrates in $\mathrm{H}_{2} \mathrm{O}$.

To explore the scope of substrates to which the NP-Pd(II) is applicable, a wide range of aqueous Suzuki reactions was investigated. Using the NP-Pd(II), all reactions employing various aryl bromide or iodide substrates proceeded smoothly and gave excellent yields (Table 2, entries 8-16). It should be noted that the coupling of 2-bromotoluene required harsher conditions, indicating a possible steric effect in the reaction (Table 2, entry 11). In Suzuki coupling, chlorobenzenes are a challenging class of substrates to convert. However, employing NP-Pd(II) with $0.5 \mathrm{~mol} \% \mathrm{Pd}$ as the catalyst, a yield of $91 \%$ was obtained (Table 2, entries 17 and 18). Moreover, a sulfur-bearing substrate, 2-bromothiophene, was efficiently converted at $60{ }^{\circ} \mathrm{C}$, with a yield of $95 \%$ achieved in $8 \mathrm{~h}$ (Table 2, entry 19). Phenylboronic acids with different substituents were also investigated; 4- $\mathrm{Cl}$ and $4-\mathrm{CH}_{3}$ phenylboronic acids were converted equally effectively, while 4-vinylphenylboronic acid was less active (Table 2, entries 20-22).

\section{Conclusions}

A facile and readily scalable synthetic strategy has been developed to yield an efficient nanoparticulate polyacetylene-supported Pd(II) catalyst for Suzuki coupling. The catalyst was obtained by simply treating an aqueous solution of $\mathrm{PdCl}_{4}{ }^{2-}$ with acetylene under ambient conditions, and comprised micron-sized aggregates of fine nanoparticles of the Pd(II)-polyacetylene complex. Systematic structural characterization revealed that $\mathrm{Pd}(\mathrm{II})$ atoms in the catalyst were homogenously distributed in the polyacetylene matrix and coordinated with $\mathrm{C}=\mathrm{C}$ and $\mathrm{Cl}$ ligands. The homogenous catalyst-like local structure and the heterogeneous catalyst-like morphology render the as-prepared catalyst both highly efficient and recyclable when applied to the aqueous Suzuki coupling of a wide range of aromatic substrates. In principle, almost all alkynes 
will readily react with $\mathrm{Pd}(\mathrm{II})$ to give polymeric complexes [34], thus the method reported herein is expected to be extendable to alkynes other than acetylene. By varying the acetylene substituent groups, it should be possible to synthesize more advanced Pd catalysts.

\section{Acknowledgments}

We thank Dr. Jyh-Fu Lee and Prof. Soofin Cheng for helpful discussions, and also the technical support from beamline 01C1 at National Synchrotron Radiation Research Center (Hsinchu). P.Z. also acknowledges the funding from NSERC Canada.

\section{References}

[1] Wijngaarden R I, Westerterp K R, Kronberg A, Bos A. Industrial catalysis: Optimizing Catalysts and Processes. Weiheim: Wiley, 2008

[2] Bhaduri S, Mukesh D. Homogeneous Catalysis: Mechanism and Industrial Applications. Weiheim: Wiley, 2000

[3] Van Leeuwen P W N M, Leeuwen P W. Homogeneous Catalysis: Understanding the Art. New York: Springer, 2005

[4] Trost B M. Angew Chem Int Ed, 1995, 34: 259

[5] Behr A, Neubert P. Applied Homogeneous Catalysis. Weiheim: Wiley, 2012

[6] Cole-Hamilton D J. Science, 2003, 299: 1702

[7] Ertl G, Knozinger H, Schuth F, Weitkamp J. Handbook of Heterogeneous Catalysis. Weiheim: Wiley, 2008

[8] Molnar A. Chem Rev, 2011, 111: 2251

[9] Polshettiwar V, Len C, Fihri A. Coord Chem Rev, 2009, 253: 2599

[10] Lu J, Toy P H. Chem Rev, 2009, 109: 815

[11] McMorn P, Hutchings G J. Chem Soc Rev, 2004, 33: 108

[12] Collis A E, Horvath I T. Catal Sci Technol, 2011, 1: 912

[13] Phan N T S, Van Der Sluys M, Jones C W. Adv Synth Catal, 2006, 348: 609
[14] Pagliaro M, Pandarus V, Ciriminna R, Beland F, Demma Carà P. ChemCatChem, 2012, 4: 432

[15] Johansson Seechurn C C, Kitching M O, Colacot T J, Snieckus V. Angew Chem Int Ed, 2012, 51: 5062

[16] Miyaura N. Top Curr Chem, 2002, 219: 11

[17] Suzuki A.J Organomet Chem, 1999, 576: 147

[18] Nicolaou K C, Bulger P G, Sarlah D. Angew Chem Int Ed, 2005, 44: 4442

[19] Miyaura N, Suzuki A. Chem Rev, 1995, 95: 2457

[20] Magano J, Dunetz J R. Chem Rev, 2011, 111: 2177

[21] Kambe N, Iwasaki T, Terao J. Chem Soc Rev, 2011, 40: 4937

[22] Littke A F, Fu G C. Angew Chem Int Ed, 1998, 37: 3387

[23] Surry D S, Buchwald S L. Chem Sci, 2011, 2: 27

[24] Wu X F, Neumann H, Beller M. ChemSusChem, 2013, 6: 229

[25] Böhm V P W, Gstöttmayr C W K, Weskamp T, Herrmann W A.J Organomet Chem, 2000, 595: 186

[26] Marion N, Nolan S P. Acc Chem Res, 2008, 41: 1440

[27] Valente C, Calimsiz S, Hoi K H, Mallik D, Sayah M, Organ M G. Angew Chem Int Ed, 2012, 51: 3314

[28] Nájera C, Gil-Moltó J, Karlström S, Falvello L R. Org Lett, 2003, 5: 1451

[29] Buchmeiser M R, Wurst K. J Am Chem Soc, 1999, 121: 11101

[30] Beletskaya I P, Cheprakov A V. J Organomet Chem, 2004, 689: 4055

[31] Kim K S, Gossmann A F, Winograd N. Anal Chem, 1974, 46: 197

[32] Kumar G, Blackburn J R, Albridge R G, Moddeman W E, Jones M M. Inorg Chem, 1972, 11: 296

[33] Wang X F, Andrews L.J Phys Chem A, 2003, 107: 337

[34] Maitlis P M. Acc Chem Res, 1976, 9: 93

[35] Abraham R, Mobli M. Modelling ${ }^{1} \mathrm{H}$ NMR Spectra of Organic Compounds. Weinheim: Wiley, 2008

[36] Elding L. Inorg Chim Acta, 1972, 6: 647

[37] Lichtmann L S, Imhoff E A, Sarhangi A, Fitchen D B. J Chem Phys, 1984, 81: 168

[38] McIntire M, Zhao L, Kobryanskii V, Chronister E. J Raman Spectrosc, 2011, 42: 1435

[39] Grogan M J, Nakamoto K. J Am Chem Soc, 1968, 90: 918

\section{Graphical Abstract}

Chin. J. Catal., 2015, 36: 1560-1572 doi: 10.1016/S1872-2067(15)60930-5

\section{A nanoparticulate polyacetylene-supported Pd(II) catalyst combining the advantages of homogeneous and heterogeneous catalysts}

Huan Li *, Guangxu Chen, Paul N. Duchesne, Peng Zhang, Yan Dai, Huayan Yang, Binghui Wu, Shengjie Liu, Chaofa Xu, Nanfeng Zheng * Xiamen University, China; Shanxi University, China; Dalhousie University, Canada

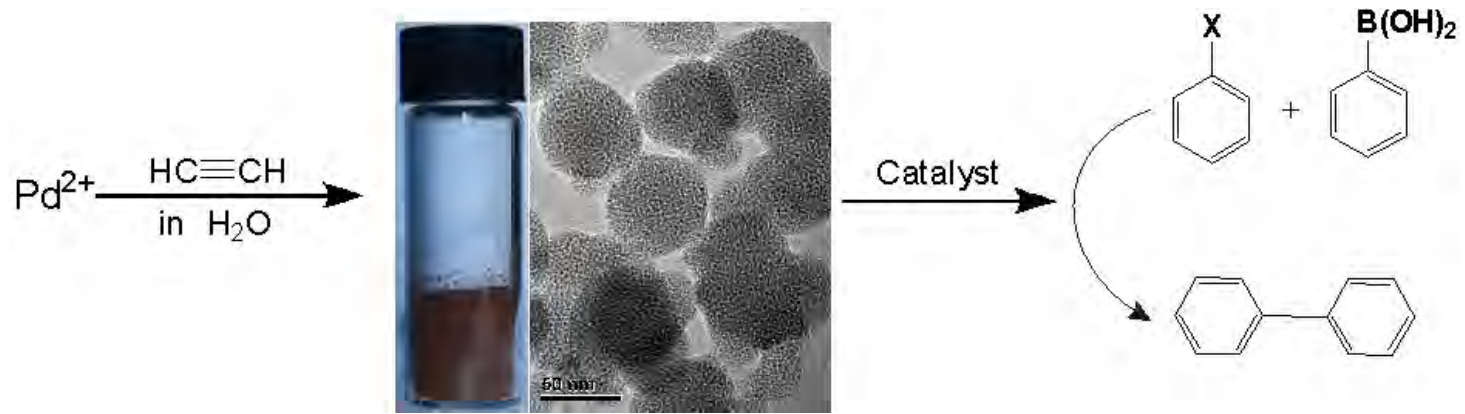

Reacting acetylene with an aqueous $\mathrm{PdCl}_{4}{ }^{2-}$ solution allows the facile and readily scalable synthesis of a nanoparticulate polyacetylene-supported Pd(II) catalyst that exhibits excellent activity in aqueous Suzuki-Miyaura coupling reactions. 
[40] Cooper D G, Powell J. Inorg Chem, 1976, 15: 1959

[41] Bernard G M, Wasylishen R E, Phillips A D. J Phys Chem A, 2000, 104: 8131

[42] Bennett M A. Chem Rev, 1962, 62: 611

[43] Jain V K, Jain L. Coord Chem Rev, 2005, 249: 3075

[44] Hartley F R. Chem Rev, 1969, 69: 799

[45] Sobczak J W, Sobczak E, Lesiak B, Palczewska W, Kosinski A.J Alloy Compd, 1999, 286: 98

[46] Negishi E I, De Meijene A. Handbook of Organopalladium Chemistry for Organic Synthesis. Weinheim: Wiley, 2002

[47] Fairlamb I J S. Org Biomol Chem, 2008, 6: 3645

[48] Scheuermann G M, Rumi L, Steurer P, Bannwarth W, Mülhaupt R. J
Am Chem Soc, 2009, 131: 8262

[49] Lamblin M, Nassar-Hardy L, Hierso J C, Fouquet E, Felpin F X. Adv Synth Catal, 2010, 352: 33

[50] Polshettiwar V, Decottignies A, Len C, Fihri A. ChemSusChem, 2010, 3: 502

[51] Badone D, Baroni M, Cardamone R, Ielmini A, Guzzi U.J Org Chem, 1997, 62: 7170

[52] Uozumi Y, Nakai Y. Org Lett, 2002, 4: 2997

[53] Ganesamoorthy S, Shanmugasundaram K, Karvembu R. J Mol Catal A, 2013, 371: 118

[54] Liu C, Zhang Y X, Liu N, Qiu J S. Green Chem, 2012, 14: 2999

[55] Leadbeater N E. Chem Commun, 2005: 2881

\title{
一种结合均相和非均相催化剂优势的聚乙炔纳米颗粒负载的钯(II)催化剂
}

\author{
李 欢 ${ }^{a, b, \# \text {, 陈光需 }}{ }^{\mathrm{a}}$, Paul N. Duchesne ${ }^{\mathrm{c}}$, 张 鹏 ${ }^{\mathrm{c}}$, 代 燕 ${ }^{\mathrm{a}}$, 杨华艳 ${ }^{\mathrm{a}}$, 吴炳辉 ${ }^{\mathrm{a}}$, \\ 刘圣洁 ${ }^{\mathrm{a}}$, 许潮发 ${ }^{\mathrm{a}}$, 郑南峰 ${ }^{\mathrm{a}}$ * \\ a厦门大学化学化工学院化学系, 固体表面物理化学国家重点实验室, 能源材料化学协同创新中心, 福建厦门361005 \\ ${ }^{\mathrm{b}}$ 山西大学晶态材料研究所, 山西太原030006 \\ c达尔豪斯大学化学系, 哈利法克斯B3H 4R2, 加拿大
}

\begin{abstract}
摘要: 负载型的金属催化剂虽然分离方便, 但在反应活性、选择性以及催化剂的结构表征方面均明显不如相应的均相催化剂. 将 均相催化剂通过不同的化学键固载于高比表面积载体是实现均相催化剂多相化的重要途径, 这样可使催化剂兼具均相和多相催 化剂的优势. 然而要将均相催化剂针定于特定载体上, 通常涉及较为复杂的合成反应, 对载体也有严格的要求. 因而该法仅仅适 用于实验室研究, 难以实现规模生产. 因此, 提供一种简便有效地制备兼具均相和多相催化剂优势的催化剂合成方法非常必要.

本文报道一种简便的制备聚乙炔纳米颗粒负载Pd(II)催化剂(NP-Pd(II))的方法, 所制催化剂在水相中的Suzuki-Miyaura偶联反 应中表现出极高的活性, 同时具有便于分离、容易放大制备的特点. 在室温下, 将乙炔气通入 $\mathrm{PdCl}_{4}{ }^{2-}$ 的水溶液中迅速变得浑浊, 静 置后容器底部有棕色沉淀, 同时溶液变为无色透明. 固体产物使用水、乙醇等溶剂进行洗涤; 干燥之后收集既得聚乙炔纳米颗粒 负载的Pd(II)催化剂NP-Pd(II). 使用透射电子显微镜、红外(IR)及拉曼吸收光谱、X射线衍射(XRD)、X射线光电子能谱(XPS)以及 X射线吸收光谱(EXAFS)等手段对NP-Pd(II)进行了详细表征. 结果显示, 在NP-Pd(II)中Pd并非以Pd纳米颗粒形式存在; XRD中没 有未Pd纳米晶的特征衍射峰. IR等表征证明乙炔在Pd的催化作用下发生聚合作用, 生成了聚乙炔. EXAFS结果表明, Pd分别和氯 原子以及 $\mathrm{C}=\mathrm{C}$ 双键进行配位; 同时, 没有观察到 $\mathrm{Pd}-\mathrm{Pd}$ 键的生成, 进一步证明了 $\mathrm{Pd}$ 未被还原为 $\mathrm{Pd}$ 纳米颗粒. XPS也印证了 $\mathrm{Pd}(\mathrm{II})$ 的 价态. 形貌上, NP-Pd(II)为直径 $2-3 \mathrm{~nm}$ 的颗粒, 其中的Pd原子均匀分散于聚乙炔纳米颗粒上, 使其在反应过程中能够充分地与底物 接触, 从而在Suzuki-Miyaura偶联反应中表现出极高的活性. 更重要的是, 由于“憎水效应”, NP-Pd(II)在溶液中以微米级的聚集体 形式存在, 因而反应后通过离心或者静置从反应体系中分离出来. 因此, 在NP-Pd(II)催化剂中, 每个Pd原子都是潜在的活性中心, 这与典型的均相催化剂相似; 同时, 其独特的形貌使其具备了多相催化剂便于分离的特点. 因此, NP-Pd(II)是一种兼具均相和多 相催化剂优点的催化剂且其催化剂的制备方法极为简便. 乙炔是常用的工业气体, 溶剂采用水, 制备在室温下即可完成, 我们也 成功地制备出克级规模的高活性、稳定性的NP-Pd(II)催化剂.
\end{abstract}

关键词: Suzuki偶联; 乙炔; 钯配合物; 水性反应

收稿日期: 2015-04-26. 接受日期: 2015-06-05. 出版日期: 2015-09-20.

*通讯联系人. 电话: (0592)2186821; 传真: (0592)2183047; 电子信箱: nfzheng@xmu.edu.cn

\#通讯联系人. 电话: (0351)7016082; 电子信箱: 59584340@sxu.edu.cn

基金来源: 科技部纳米研究国家重大科学研究计划(2011CB932403, 2015CB932303); 国家自然科学基金(221420102001, 21131005, 21390390, 21333008).

本文的英文电子版由Elsevier出版社在ScienceDirect上出版(http://www.sciencedirect.com/science/journal/18722067).

\section{Supporting Information}

\section{Method for fitting the fourier-transformed EXAFS spectrum of NP-Pd(II)}

Based on analysis of the NP-Pd(II) EXAFS spectrum, it was concluded that only two scattering paths were present in the sample, Pd-C and Pd-Cl. The Debye-Waller factor and $E_{0}$ shift values of the $\mathrm{Pd}-\mathrm{C}$ and $\mathrm{Pd}-\mathrm{Cl}$ coordination shells were assumed to be equal, given the fact that the values of these parameters should be similar in any reliable fitting of experimental data. To fit the EXAFS curve of NP-Pd(II), establishing a coordination 
pattern model of $\mathrm{Pd}$ is critical. Although the available ligands are simply acetylene and chloride, a number of possible coordination isomers exist. Likely as a result of this variability, the products of the reaction between acetylene and $\mathrm{Pd}$ chloride were usually defined as "uncharacterizable" [1,2]. Therefore, considering the fact that the Pd coordination pattern might not represent a single isomer, randomly selecting one of them as a fitting model would be arbitrary and could lead to unreasonable results. Hence, based on a basic understanding of the possible structures, we have proposed a simplified model for EXAFS fitting. In this model, two different types of bonds, two Pd-C and two Pd-Cl were established. These four bonds are in the same plane because $\mathrm{Pd}(\mathrm{II})$ usually favors a planar four-coordinate geometry. The positions of the $\mathrm{Cl}^{-}$ligands were taken from the structure of $\mathrm{PdCl}_{2}$, and two adjacent $\mathrm{Cl}^{-}$ligands of the original four were then replaced with $\mathrm{C}$ atoms. The bond lengths were

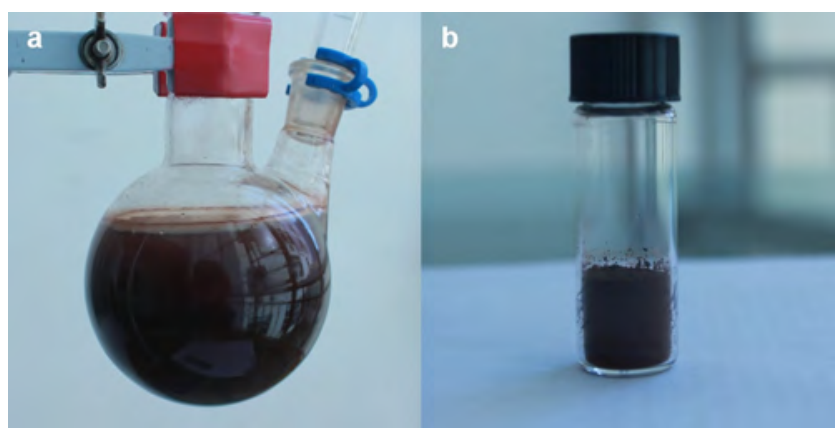

Fig. S1. Photos of (a) the colloidal suspension formed after introduction of acetylene into the aqueous $\mathrm{PdCl}_{4}^{2-}$ solution and (b) 1 gram of dry NP-Pd(II) powder separated from a).

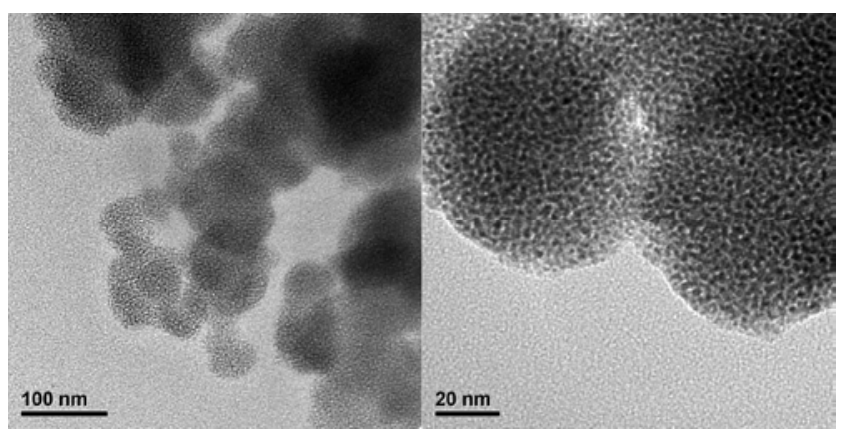

Fig. S2. TEM images of NP-Pd(II)-1atm prepared under 1 atm $\mathrm{C}_{2} \mathrm{H}_{2}$.

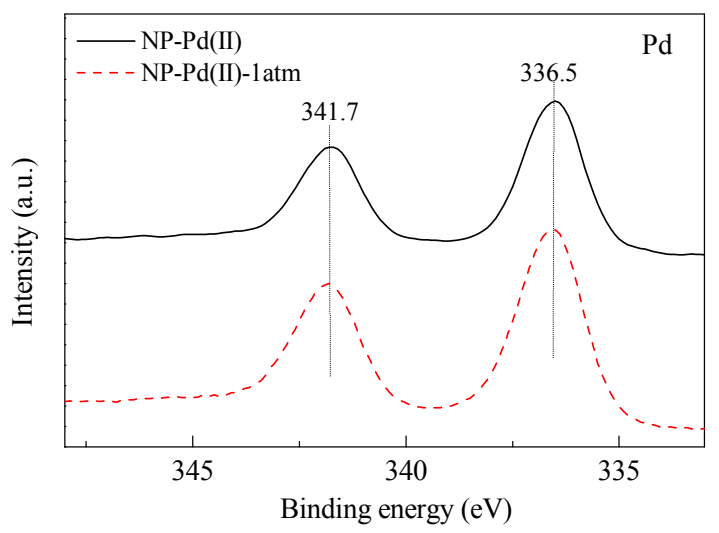

Fig. S3. Comparison of XPS spectra of NP-Pd(II) and NP-Pd(II)-1atm.
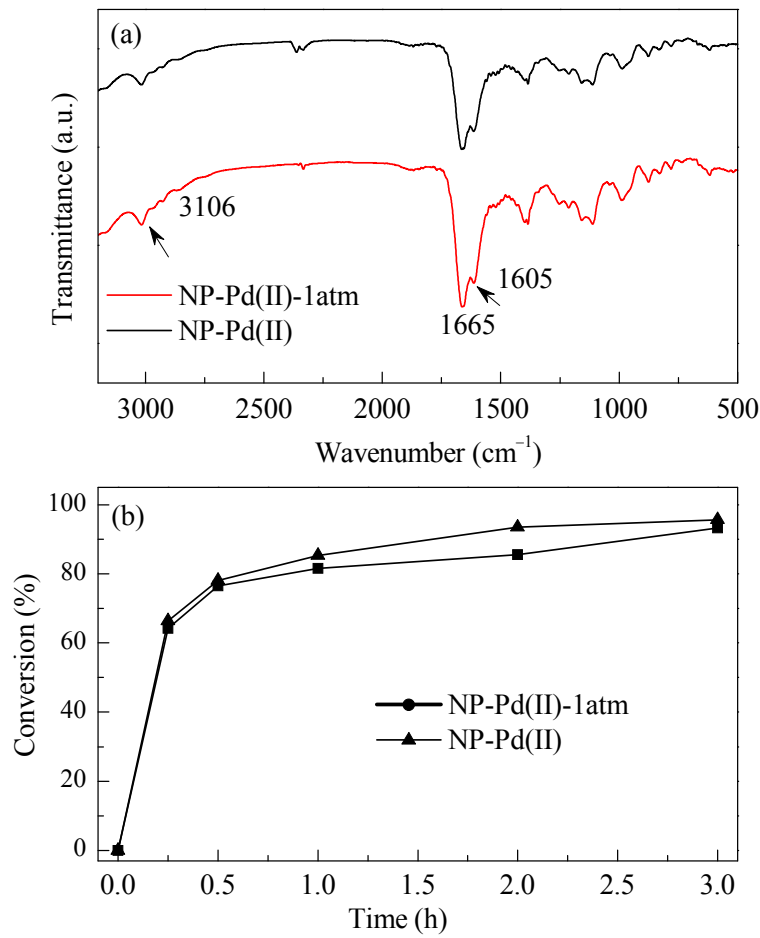

Fig. S4. FT-IR spectra and activity study of NP-Pd(II), NP-Pd(II)-1atm. Reaction condition: $0.1 \mathrm{~mol} \% \mathrm{Pd}, 10 \mathrm{~mL}$ ethanol and $5 \mathrm{~mL} \mathrm{H} \mathrm{H}_{2} \mathrm{O}, 1 \mathrm{mmol}$ iodobenzene, $1.5 \mathrm{mmol}$ phenylboronic acid, $2 \mathrm{mmol} \mathrm{Na}_{2} \mathrm{CO}_{3}, 30^{\circ} \mathrm{C}$.

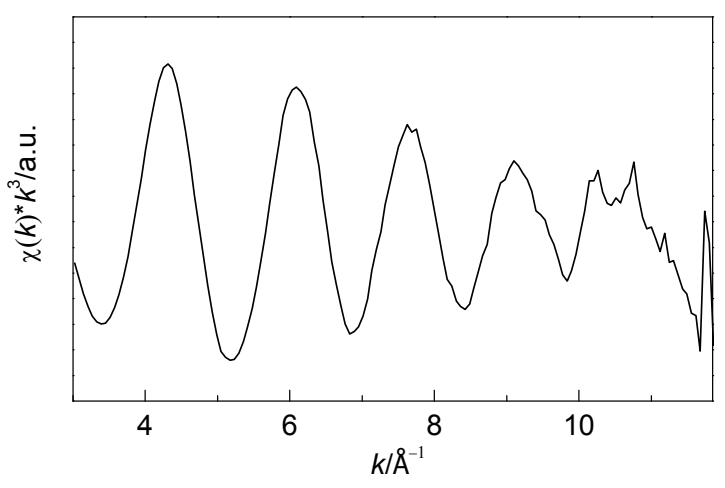

Fig. S5. $k$-space XAFS spectrum of NP-Pd(II).

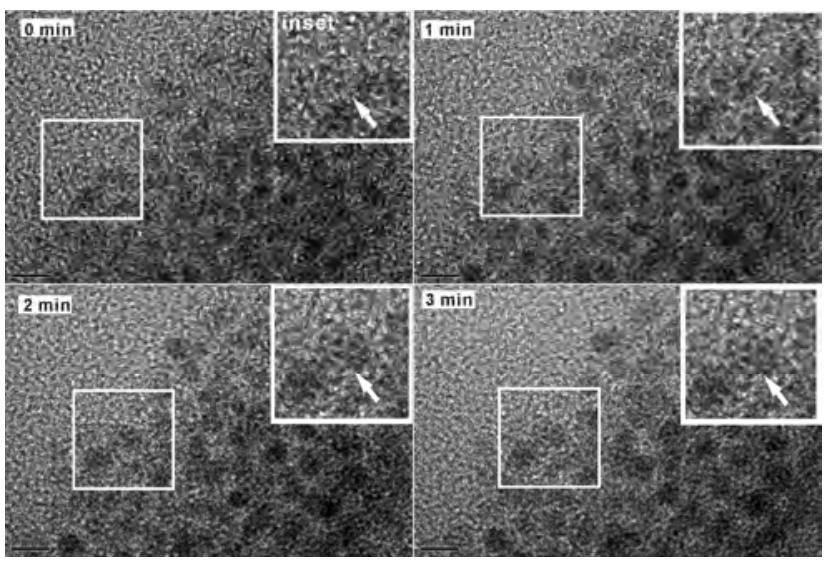

Fig. S6. The gradual formation of Pd nanoparticles under irradiation of the electron beam during the TEM measurements on NP-Pd(II). Inset is the magnified image. 
then adjusted using available atom radius information [3]. In this simplified model, both of the Pd-C paths and both of the $\mathrm{Pd}-\mathrm{Cl}$ atoms are identical Thus, only two scattering paths were generated by the FEFF8 program. These paths were then introduced into the fitting of EXAFS using WinXAS software according to standard procedures. Using this model, meaningful fits of the data were successfully achieved, with good agreement between the experimental data and fitting curve (see Fig. 4(b)), thereby indicating the validity of the model.

The molar ratio of $\mathrm{Pd}$ to $\mathrm{Cl}$ from elemental analysis is $\mathrm{ca}$. $1: 2.1$, and the average coordination number $(\mathrm{CN})$ of $\mathrm{Cl}$ to $\mathrm{Pd}$ from the EXAFS fitting (see text) is 2.4. Furthermore, the CN of the $\mathrm{C}$ atom from EXAFS fitting is 2.2. FT-IR, ${ }^{13} \mathrm{C}$ NMR, RAMAN, EXAFS all showed the presence of $\mathrm{C}=\mathrm{C}$ being coordinated with $\mathrm{Pd}$. Accordingly, based on all the given information, we proposed that NP-Pd(II) may consist of two possible Pd coordination patterns, which are presented in Fig. S8. Both of these structures are very commonly observed in various olefin complexes of Pd [4].

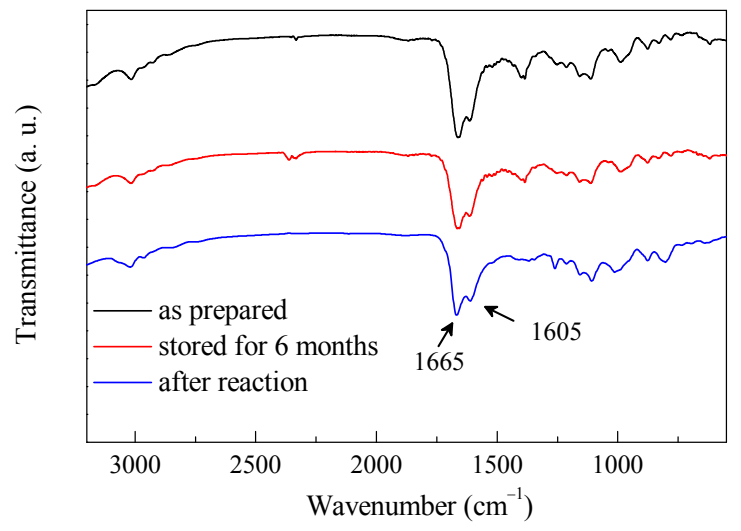

Fig. S7. FT-IR of NP-Pd(II): freshly made (black line), stored in open air for 6 months at room temperature (red line), and after reaction (blue line).
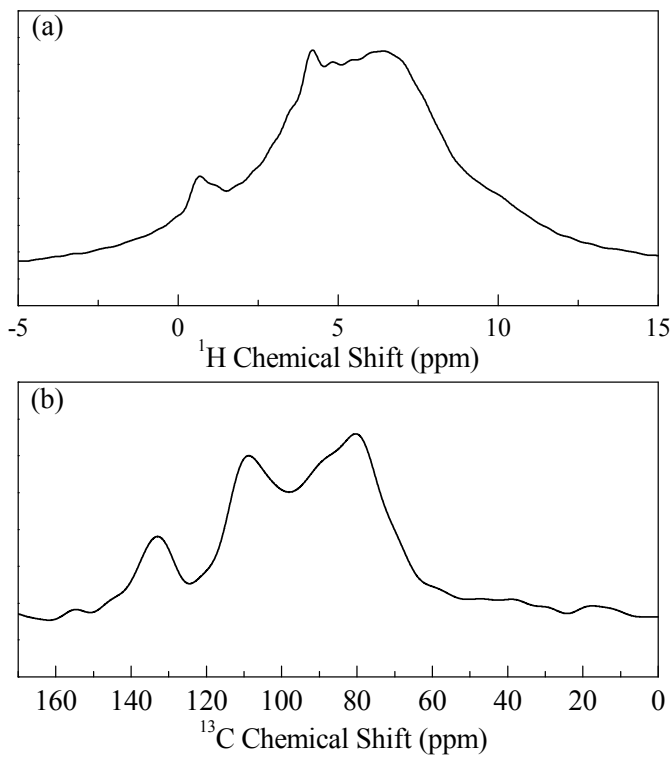

Fig. S8. Solid state a) ${ }^{1} \mathrm{H}$ and b) ${ }^{13} \mathrm{C}$ NMR spectra of NP-Pd(II).

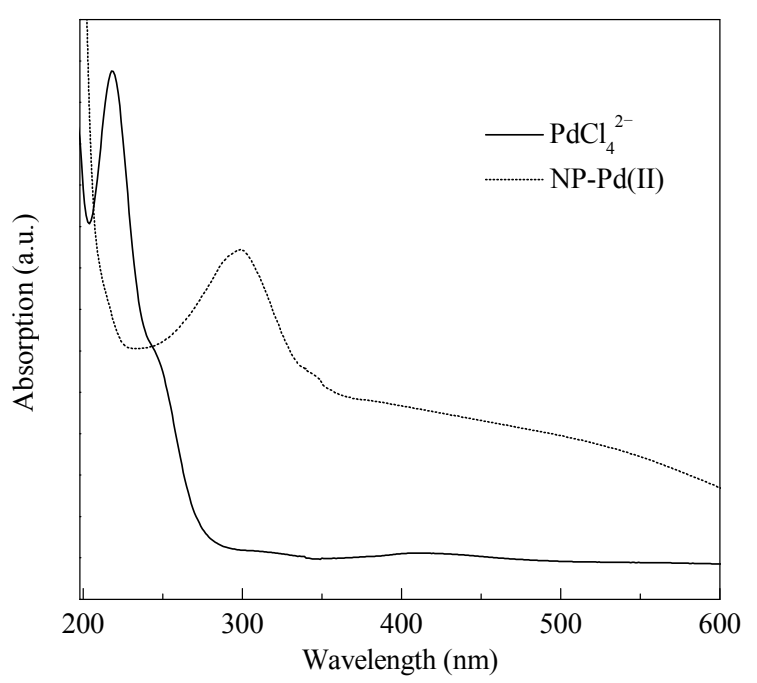

Fig. S9. UV-Vis spectra of NP-Pd(II) suspension and $\mathrm{PdCl}_{4}{ }^{2-}$ solution.

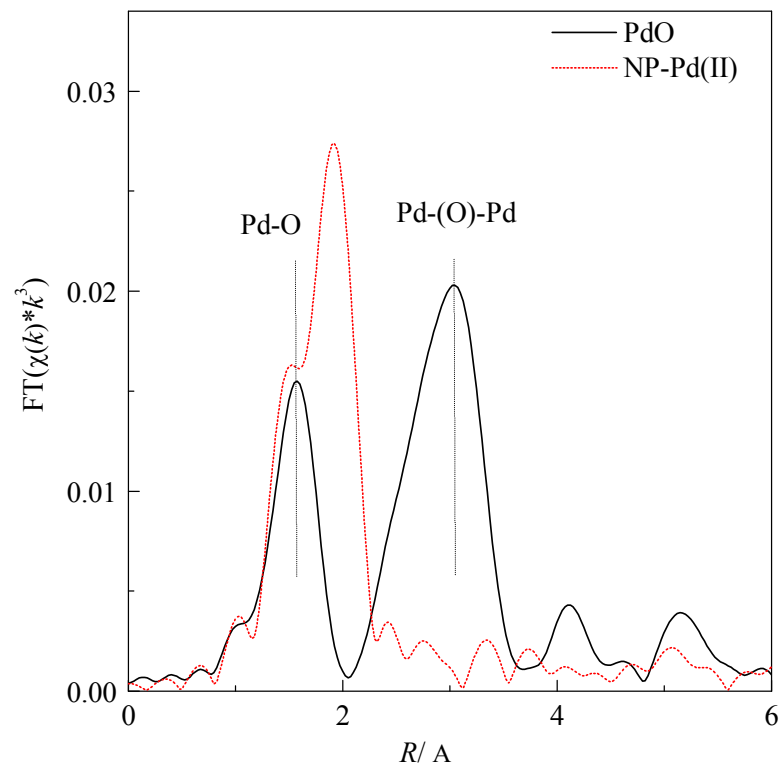

Fig. S10. EXAFS spectra of NP-Pd(II) and PdO.
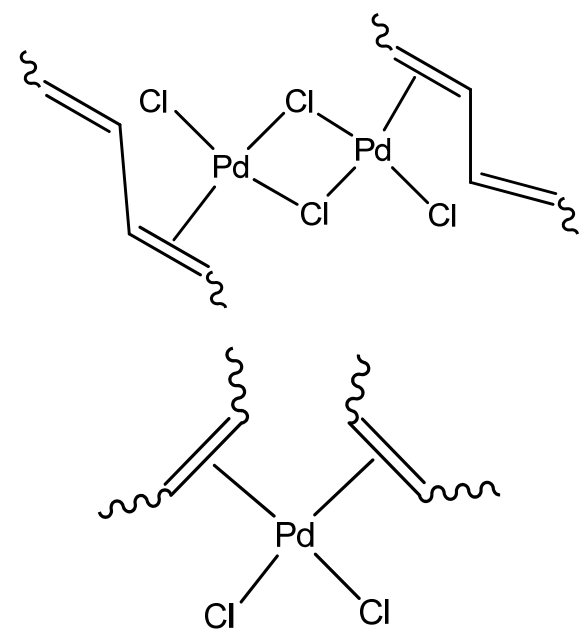

Fig. S11. The two proposed local structures of NP-Pd(II). 


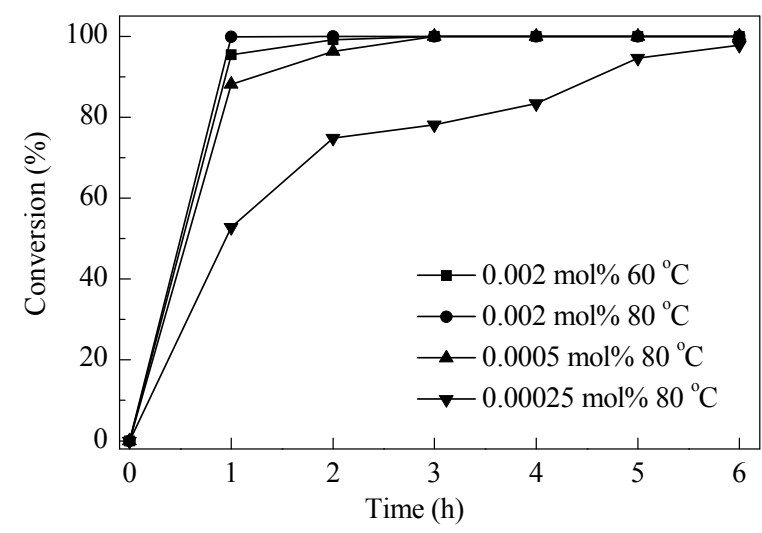

Fig. S12. Suzuki coupling of iodobenzene with phenylboronic acid by NP-Pd(II) with different catalyst-to-substrate ratios. Reaction conditions: $10 \mathrm{~mL}$ ethanol and $5 \mathrm{~mL} \mathrm{H}_{2} \mathrm{O}, 1 \mathrm{mmol}$ iodobenzene, $1.5 \mathrm{mmol}$ phenylboronic acid, $2 \mathrm{mmol} \mathrm{Na}_{2} \mathrm{CO}_{3}$.

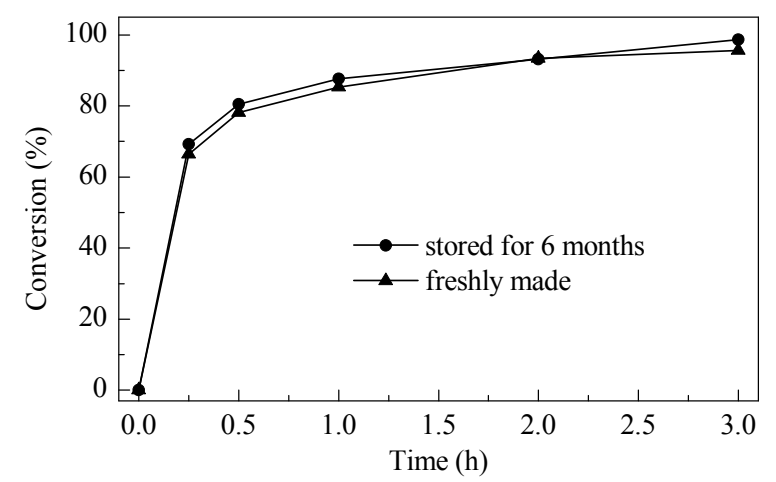

Fig. S13. Suzuki coupling of iodobenzene with phenylboronic acid by fresh NP-Pd(II) and the one stored for 6 months at ambient conditions. Reaction conditions: $0.1 \mathrm{~mol} \% \mathrm{Pd}, 10 \mathrm{~mL} \mathrm{EtOH}$ and $5 \mathrm{~mL} \mathrm{H}_{2} \mathrm{O}, 1 \mathrm{mmol}$ iodobenzene, $1.5 \mathrm{mmol}$ phenylboronic acid, $2 \mathrm{mmol} \mathrm{Na}_{2} \mathrm{CO}_{3}, 30^{\circ} \mathrm{C}$.
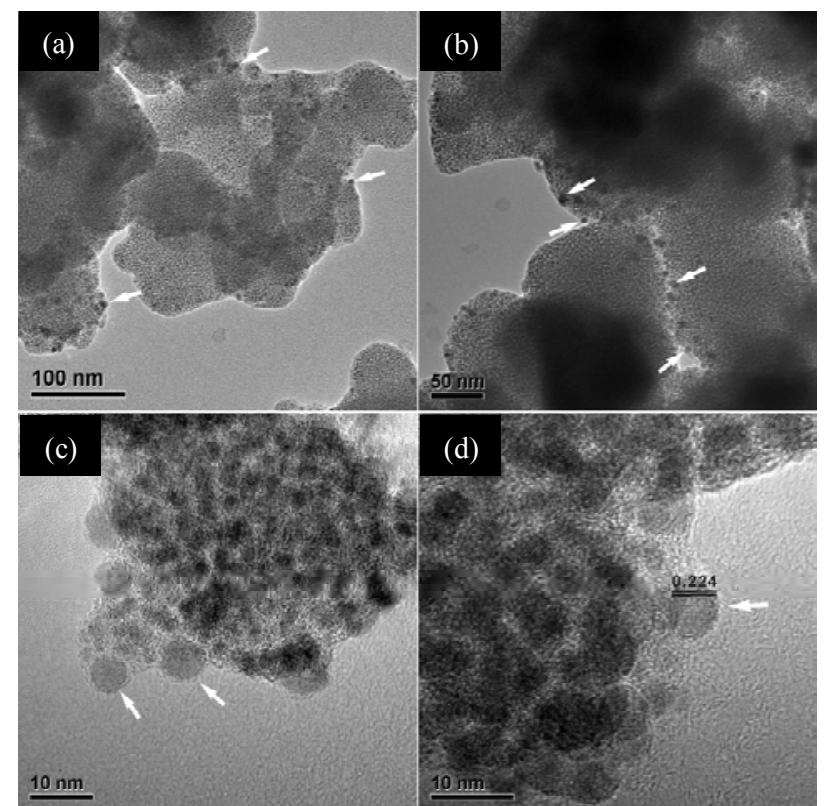

Fig. S14. TEM images of NP-Pd(II) after used. White arrows indicated the presence of Pd nanoparticles and the HR-TEM in (d) showed a interplanar spacing of $0.224 \mathrm{~nm}$, corresponding to that of $\mathrm{Pd}(111)$.

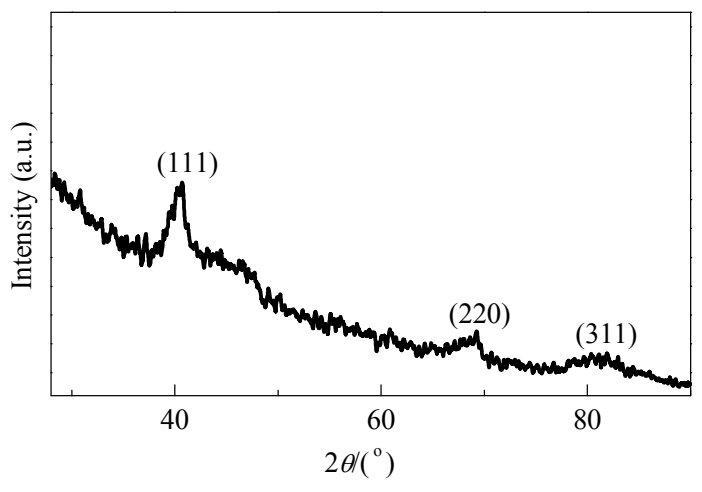

Fig. S15. XRD pattern of NP-Pd(II) after use.

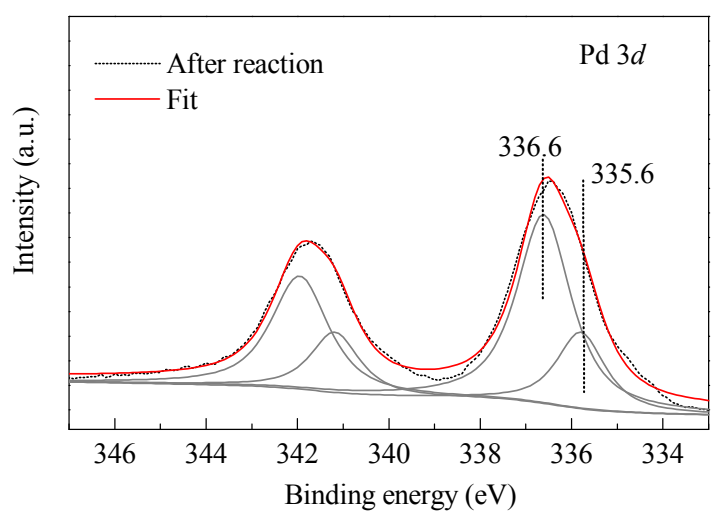

Fig. S16. XPS and its fitting of NP-Pd(II) after reaction. Black dot represents experimental data. Red solid line is the fitting result. Each peak can be divided into two parts. One part with a higher binding energy is ascribed to NP-Pd(II), the other one is due to $\mathrm{Pd}(0)$.
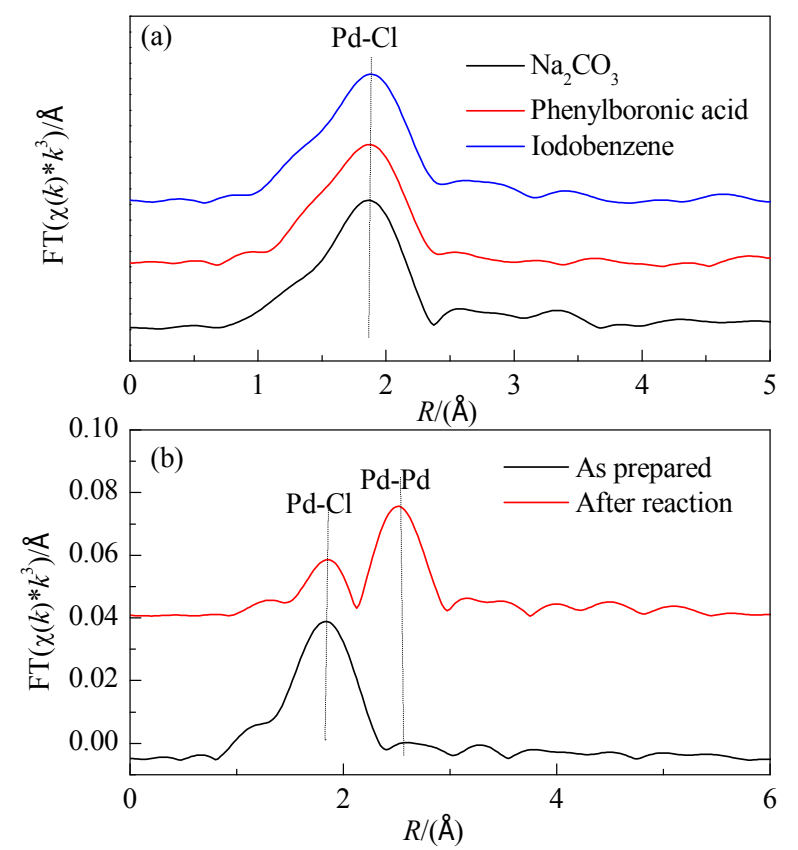

Fig. S17. Deactivation mechanism study of NP-Pd(II) by EXAFS. (a) NP-Pd(II) was dispersed into $\mathrm{H}_{2} \mathrm{O}$, then $\mathrm{Na}_{2} \mathrm{CO}_{3}$ (phenylboronic acid or iodobenzene) was added and the mixture was treated at reaction conditions for $1 \mathrm{~h}$ before it was analyzed by EXAFS. (b) EXAFS of NP-Pd(II) before and after reaction. 

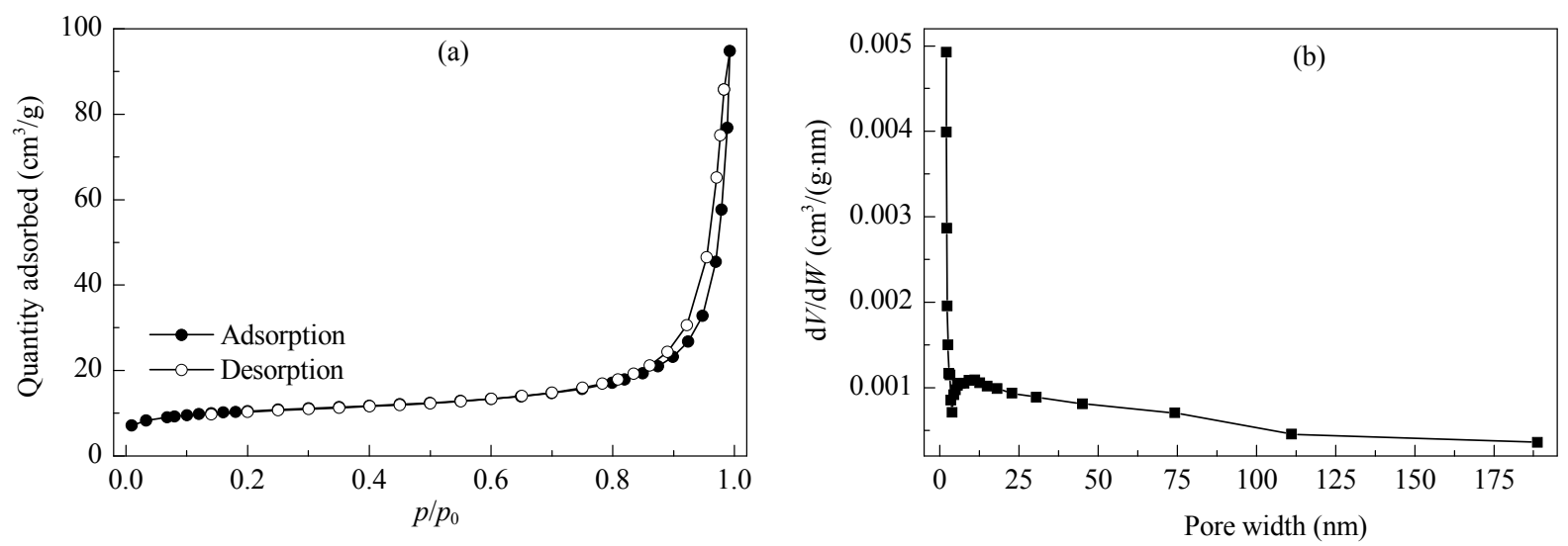

Fig. S18. $\mathrm{N}_{2}$ adsorption isotherms (a) and pore-size distribution (b) of NP-Pd(II). BET surface area $37 \mathrm{~m}^{2} / \mathrm{g}$, pore volume $0.14 \mathrm{~cm}^{3} / \mathrm{g}$.

\section{References}

[1] Maitlis P M. ACC Chem Res, 1976, 9: 93
[2] Greaves E 0, Lock C J L, Maitllis P M. Can J Chem, 1968, 46: 3879

[3] See: http://www.webelements.com/palladium/atom_sizes.html

[4] Negishi E I. Handbook of Organopalladium Chemistry for Organic Synthesis. Weinheim: John Wiley \& Sons, 2002 